\title{
GAÚCHOS VERSUS NÃO GAÚCHOS: O USO DE LÍNGUA ADICIONAL PARA A CONSTRUÇÃO DE IDENTIDADES SOCIAIS E OPOSIÇÕES INTERACIONAIS EM SALA DE AULA
}

\section{GAÚCHOS VERSUS NÃO GAÚCHOS: THE USE OF ADDITIONAL LANGUAGE TO CO- CREATE SOCIAL IDENTITIES AND INTERACTIONAL OPPOSITIONS IN THE CLASSROOM}

\author{
Laura Knijnik Baumvol \\ Doutoranda em Linguística Aplicada pela Universidade Federal do Rio Grande do Sul \\ Professora da Universidade do Vale do Rio dos Sinos \\ E-mail: laura.baumvol@gmail.com
}

\section{RESUMO}

O presente artigo examina a construção conjunta, local e contingente da oposição de identidades sociais pelos participantes em uma sala de aula de inglês como língua adicional, através da análise de sua fala-em-interação durante uma atividade pedagógica. A perspectiva teóricometodológica adotada baseia-se na Análise da Conversa para Aquisição de Segunda Língua (FIRTH; WAGNER, 2007; LODER; JUNG, 2008) e nos estudos das identidades e linguagem no contexto social (MOITA LOPES, 2002; HALL, 2001). O estudo permitiu averiguar que, ao longo da interação, os participantes exibem, uns para os outros, relações identitárias opostas e conflituosas, ao se darem conta de quem são e de quem não são, atuando como agentes da construção de uma polarização entre as categorias identitárias de "gaúchos" versus "não gaúchos". Tais ações foram desencadeadas por uma discordância em relação à uma posição assumida por um dos participantes, sendo, portanto, o "outro" crucial para a construção, momento-a-momento, dessas identidades sociais opostas, que não são fixas e nem podem ser pré-determinadas pelo pesquisador ou por apenas um dos envolvidos. Ao demostrar que o confronto instaurado abriu espaço para que os participantes, através do uso da linguagem, mobilizassem diferentes recursos linguísticos e extralinguísticos na língua adicional para construírem suas identidades, o estudo fornece uma contribuição para as pesquisas relacionadas a questões identitárias em sala de aula e na prática docente, trazendo elementos para que os educadores atuem de modo inclusivo e reflexivo, promovendo uma aprendizagem mais significativa e efetiva em sala de aula.

Palavras-chave: Análise da Conversa para Aquisição de Segunda Língua. Sala de Aula. Identidades Sociais. Prática Docente. 


\section{ABSTRACT}

This paper examines the joint, local and contigent construction of the opposition of social identities by participants in a classroom of English as an Additional Language, by analyzing their talk-in-interaction while performing a pedagogical activity. The research is grounded on Conversation Analysis for Second Language Acquisition (FIRTH; WAGNER, 2007; LODER; JUNG, 2008) and social identities and language studies (MOITA LOPES, 2002; HALL, 2001). The investigation showed that participants display to each other opposite and conflicting identity relations and act together building a polarization between the categories of "gauchos" versus "not gauchos" and realize who they are and who they are not while interacting. These actions were triggered by a disagreement towards a position taken by one of the participants. Therefore, the "other" is a crucial element for constructing, moment by moment, these opposing social identities, which are not fixed and can not be predetermined by the researcher, nor by only one of the participants. The analysis concludes that the dispute opened room for participants to mobilize linguistic and extralinguistic resources in the Additional Language in order to build their social identities. The study provides a contribution to the research in the field of social identities in the classroom and teaching practices, bringing elements to help educators act in an inclusive and reflective way and promote a more meaningful abd effective learning experience in the classroom.

Key-words: Conversation Analysis for Second Language Acquisition. Classroom. Social Identities. Teaching Practice.

\section{INTRODUÇÃO}

Em cada uso da linguagem situado e configurado localmente pelo professor e pelos alunos na sala de aula, diferentes questões identitárias podem emergir da interação (MOITA LOPES ,1996). Nesse sentido, a descrição e a análise do modo pelo qual as identidades se tornam relevantes são cruciais para que o professor possa compreender melhor seus alunos e, consequentemente, adaptar sua prática pedagógica a fim de proporcionar uma aprendizagem mais efetiva e inclusiva, com a qual os aprendizes se relacionem e se sintam acolhidos em suas diferenças.

O presente artigo relata os resultados de uma pesquisa qualitativa de cunho microetnográfico, que analisa a co-construção local e contigente, de identidades sociais, bem como as oposições interacionais e os conflitos identitários que emergem na interação, no 
contexto de uma sala de aula de inglês como língua adicional em um curso livre de idiomas. Busca-se proporcionar subsídios em relação à importância de o professor atentar para as categorias identitárias advindas das manifestações dos alunos que não foram planejadas ou gerenciadas por ele, as quais podem se tornar elementos importantes no processo de ensinoaprendizagem da língua.

Na primeira parte deste trabalho, são apresentados conceitos fundantes da perspectiva teórica adotada, bem como uma contextualização do tema, enfocando aspectos da fala-eminteração em sala de aula, participação e identidades sociais. Depois, apresenta-se a metodologia adotada para a análise qualitativa de cunho etnográfico e, em seguida, a análise microinteracional dos dados. Por fim, são traçadas algumas considerações finais relacionadas às implicações do estudo para a prática docente e para as pesquisas na área.

\section{ANÁLISE DA CONVERSA PARA AQUISIÇÃO DE SEGUNDA LÍNGUA, PARTICIPAÇÃO E CONSTRUÇÃO DE IDENTIDADES SOCIAIS}

A Análise da Conversa Etnometodológica (ACE) constitui-se em um tipo especial de análise social, desenvolvida a partir dos estudos de Garfinkel e Sacks (1970). Para a ACE, o entendimento da linguagem não está relacionado à compreensão de elocuções, mas sim às ações dos interagentes, que são interpretadas quanto aos seus contextos. Assim, não é possível separar o que as partes de uma conversa falam do modo como essas partes falam, sendo a ação humana necessariamente co-construída e intersubjetiva. Ao agirem, os atores sociais buscam, incessantemente, a manutenção de sua convergência de entendimentos (intersubjetividade), o que pode ser comprovado por meio do exame dos turnos de fala produzidos (SCHEGLOFF, 1991).

A base inicial para o estabelecimento dos princípios da ACE foi a análise de dados de conversa cotidiana sendo que, posteriormente, autores como Drew e Heritage (1992) propuseram o estudo da fala-em-interação "institucional”, na qual há uma orientação dos participantes para alguma meta, tarefa ou atividade fulcral, associada, por convenção, a uma instituição. O presente estudo mostra justamente aspectos da fala-em-interação no contexto institucional educativo, mas a análise empreendida não a entende como um fenômeno unicamente institucional, por haver um participante (o professor) que tradicionalmente orienta-se para a meta da aula. Pelo contrário, existem várias falas-em-interação que ocorrem simultaneamente, em um "nexo de sistemas de troca de falas inter-relacionados" (MARKEE; KASPER, 2004, p. 492). 
O presente trabalho afilia-se a um campo que tem se estabelecido de modo consistente entre os estudos de ensino e aprendizagem de línguas: a Análise da Conversa para Aquisição de Segunda Língua (AC para ASL) (MONDADA; DOEHLER, 2004; FIRTH; WAGNER, 2007; PEKAREK-DOEHLER, 2010; GARDNER, 2013). Tal campo busca explorar os detalhes dos mecanismos interacionais que estabelecem e transformam as práticas em sala de aula para uma nova compreensão de como as atividades são, de fato, realizadas e entendidas pelos participantes, e quais potenciais objetos de aprendizagem emergem durante a sua execução (HELLERMAN; PEKAREK-DOEHLER, 2010).

Essa perspectiva teórica-metodológica defende a impossibilidade da manutenção da dicotomia entre uso e aquisição da linguagem, sustentada tradicionalmente pelos estudos de aquisição de segunda língua, propondo maior atenção às dimensões contextuais e interacionais do uso da linguagem e à perspectiva dos participantes (visão êmica). Entende-se a linguagem, portanto, como um fenômeno social, sendo adquirida e usada pelos interagentes para diferentes fins práticos, isto é, a linguagem não é simplesmente aplicada ao agirmos, mas (re)modelada a cada uso diante das necessidades comunicativas localmente configuradas (CLARK, 1996). Portanto, adquirir e usar uma língua são processos indissociáveis e aprendizagem de uma língua adicional está diretamente relacionada com a participação em práticas sociais que demandem dos interagentes o seu uso efetivo, nas quais suas categorias identitárias podem ser tornadas relevantes interacionalmente (PEKAREK-DOEHLER, 2010; MOITA LOPES, 1996).

Diversos estudos que analisam interações em sala de aula apontam que participação e aprendizagem estão intimamente ligados (CAZDEN, 2001; SCHULZ, 2007). Neste trabalho, adota-se a noção de participação baseada nas contribuições de Goodwin e Goodwin (2004), que incluem não apenas a tomada de turnos e o engajamento e manutenção do piso conversacional, mas também a ratificação ou não daquilo que é dito, os alinhamentos dos participantes, os ajustes dos interagentes em relação aos demais, a relação de suas ações com o cenário e com as tarefas em que se engajam, bem como sua disposição física. No dado que será analisado, a coconstrução das identidades sociais dos interagentes está diretamente ligada à ratificação de sua participação pela professora, diante de uma oposição interacional que emerge, e do novo alinhamento conjunto que se configura.

Ao partimos de uma visão de mundo social, segundo a qual a realidade social é construída conjuntamente (GIDDENS, 2005), percebemos que os participantes, em suas ações conjuntas realizadas mediante o uso da língua adicional, constroem categorias identitárias na interação e, para compreender tal fenômeno, necessitamos observar como essas identidades sociais são negociadas interacionalmente. Assim como propõe Moita Lopes (2002), a 
investigação de diferentes discursos de identidade na sala de aula em foco parte da análise do modo pelo qual os participantes constroem e dão significado à sua realidade social e a si mesmos, a partir das práticas discursivas com o outro. Nesse sentido, a contribuição de Hall (2001) em seus estudos culturais em Educação, ao apontar que o "dar-se" conta de "quem sou" e de "quem somos nós", em um determinado grupo ou comunidade, é um processo dinâmico e contínuo, essencial para nos constituirmos. Assim, as identidades sociais são categorias fluídas ao invés de fixas, sendo negociáveis a cada momento, em um processo dinâmico e contínuo.

Em diferentes contextos sociais, estabelecem-se relações assimétricas entre os interagentes e aqueles com maior poder têm maior influência e, consequentemente, são mais capazes de definir a construção social tanto do significado, como das identidades. Em sala de aula, tradicionalmente o professor assume tal posição, sendo crucial que a análise interacional leve isso em consideração em cada interação específica, ainda que haja momentos em que tal assimetria se modifique. Com efeito, não possuímos apenas uma identidade social, mas múltiplas, que podem ser exercidas ao mesmo tempo e que emergem na interação, como ocorre no dado que será analisado.

Por fim, cumpre apontar algumas noções necessárias para a análise microinteracional que será apresentada a seguir. O termo afiliação diz respeito à exibição pelo participante de seu apoio e endosso da posição/perspectiva adotada pelo falante do turno anterior. Já quando se examina se os participantes ratificam ou não os turnos de fala uns dos outros ao longo da interação, tal ratificação diz respeito às ações levadas a cabo pelos demais interagentes, ao seu alinhamento, e não a um posicionamento (STIVERS, 2008, STEENSIG, 2012). Concordar ou discordar, portanto, guarda relação com afiliar-se ou não a um posicionamento tomado por outro participantes, e não com a ação que ele realizou.

\section{METODOLOGIA}

O presente estudo foi realizado no contexto educacional de um curso livre de idiomas, na cidade de Porto Alegre. O dado examinado é oriundo de treze horas de gravações em áudio e vídeo, gerados através de três câmeras e três gravadores de voz, em uma sala de aula de inglês como língua adicional em uma turma de nível intermediário, entre abril e junho de $2009^{1}$. A turma era composta pela professora e por nove alunos de nível intermediário de inglês ${ }^{2}$ e os encontros ocorriam uma vez por semana, aos sábados, durante três horas ${ }^{3}$.

Para selecionar o dado que será examinado, as gravações em cada uma das câmeras foram assistidas por diversas vezes, utilizando como critério a ocorrência de uma contribuição do aluno relacionada a algo que parecia não ter sido previsto pela professora em seu planejamento de aula e na qual questões de identidade estivessem, de algum modo, em jogo na interação. A 
fim de transcrever tal interação, conforme as convenções Jefferson ${ }^{4}$ (ATKISON; HERITAGE, 1984; LODER, 2008), o registro selecionado foi assistidos novamente inúmeras vezes. A partir da transcrição, foram realizadas a descrição e a análise de tal momento interacional, a fim de entender como se dá a fala-em-interação, quais são as ações levadas a cabo pelos participantes durante essa atividade pedagógica e como eles lidam com questões identitárias e de oposição interacional, enquanto usam e aprendem a língua adicional.

\section{ANÁLISE INTERACIONAL}

O dado a ser analisado está inserido dentro de uma atividade pedagógica realizada a partir da página 110 do livro didático (vide Fig. 1), que envolvia um momento em duplas e em trios, no qual os participantes deveriam expressar sua opinião a partir de perguntas do livro sobre o "american lifestyle" e, posteriormente, um momento de retomada da atividade anterior em grande grupo, com a resolução de dúvidas sobre palavras e expressões, bem como a correção e prática de pronúncia e vocabulário. $\mathrm{O}$ dado ocorre no segundo momento da atividade pedagógica, quando ocorre a retomada em grande grupo.

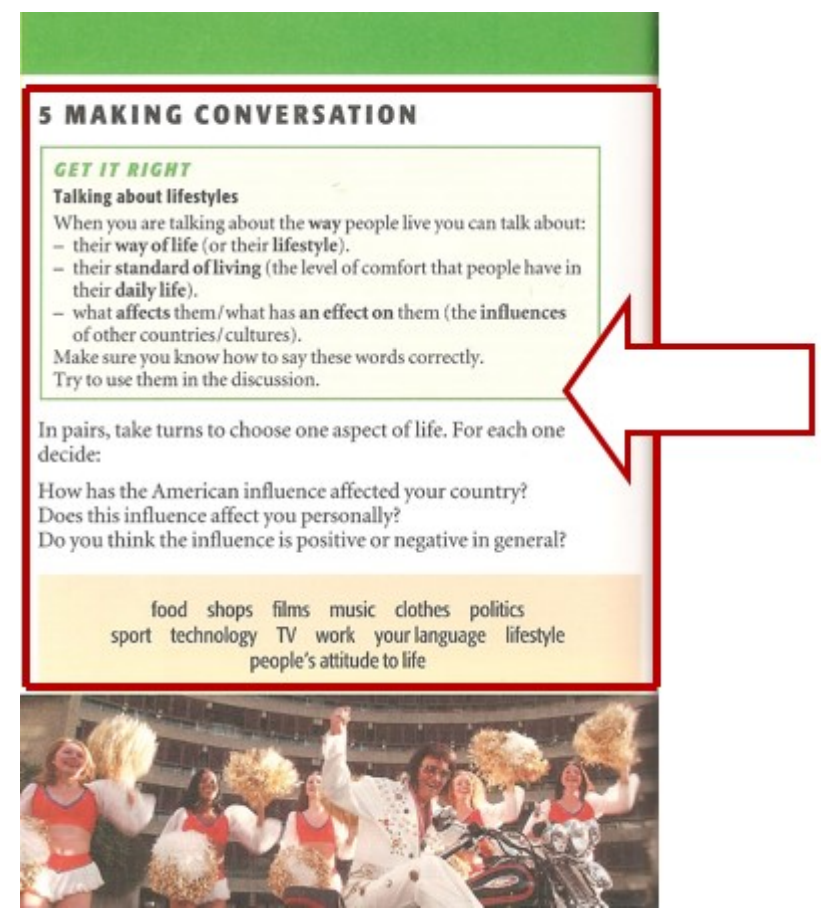

Figura 1: Página 110 do livro didático English File upper-intermediate

Fonte: English File upper-intermediate Oxford: Oxford University Press, 2009.

A seguir, apresento o dado em análise, dividido em três excertos, a fim de facilitar a leitura e o entendimento da análise interacional. 


\subsection{EXCERTO 1}

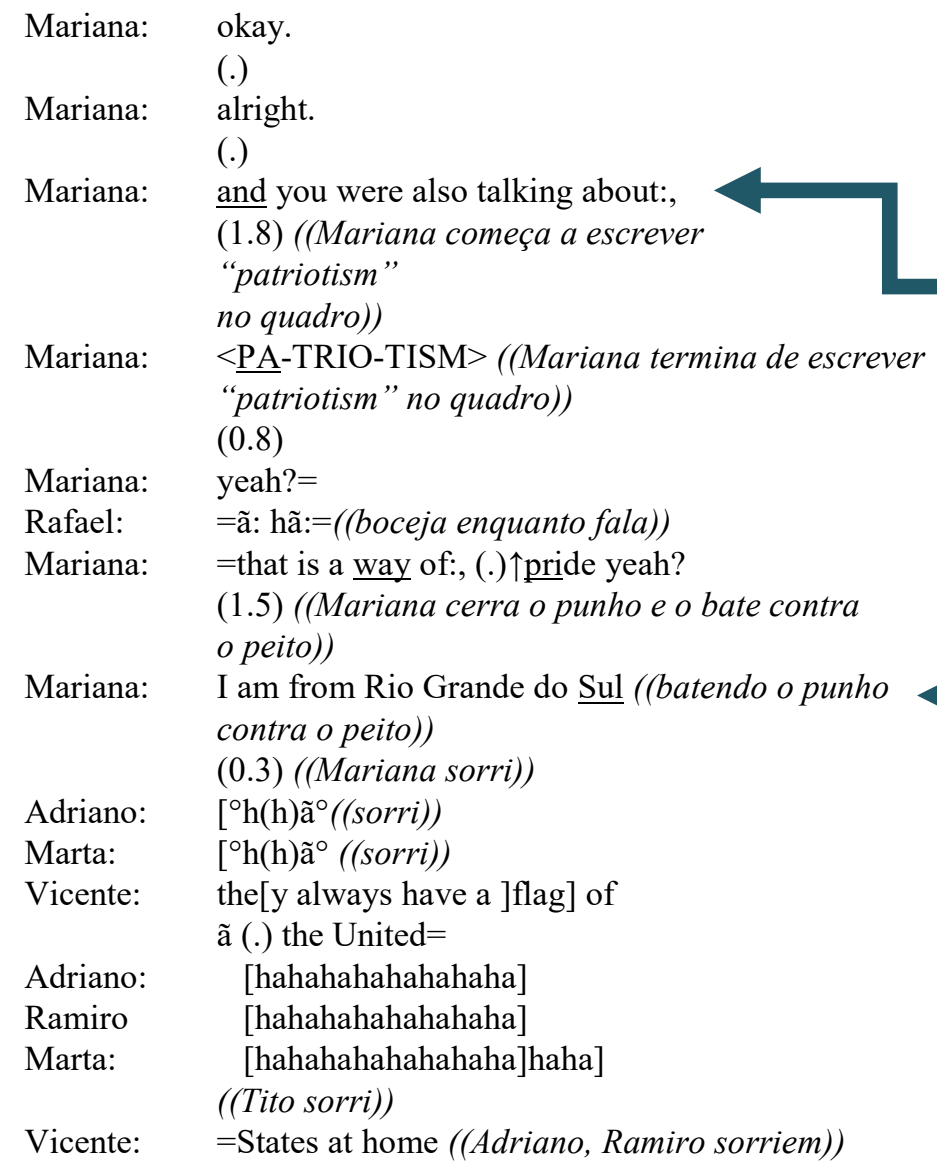

Nota-se que o excerto 1 tem início quando Mariana sugere a retomada do tópico patriotismo, sobre o qual os demais participantes haviam discutido em duplas e em trios anteriormente (linhas 5, 9 e 12). Ela escreve no quadro interativo a palavra "patriotism" e, enquanto termina de escrever, produz a elocução $<$ PA-TRIO-TISM $>$ (linha 9), em tom de voz mais alto e pausado, passando a explicar o significado do termo, solicitando a ratificação dos demais participantes e convidando-os a participar (linha 14). Para exemplificar, Mariana bate o punho direito cerrado contra o próprio peito (quadro de imagem 2) e diz I am from Rio Grande do $\underline{\text { Sul }}$ (linha 17), dando ênfase ao item "sul" ao final e sorrindo, parecendo sinalizar o orgulho de ser do sul. Adriano, Marta e Ramiro e Tito ratificam sua fala ao rirem e sorrirem (linhas 20, 21, 24, 25 e 26), enquanto Vicente toma o turno e volta ao tópico "american lifestyle", discutido anteriormente e proposto pelo livro didático, associando-o com o patriotismo norte-americano e com o fato deles sempre terem uma bandeira do seu país em casa (linhas 22, 23 e 28).

A partir desse momento, o dado passa a ter dois focos interacionais, ocorrendo o cisma ${ }^{5}$ da interação anterior em dois pisos conversacionais distintos, o que parece ter sido desencadeado pelo turno de fala de Mariana de linha 17. 


\subsection{EXCERTO 2}

1
2
3
4
5
6
7
8
9
10
11

2

3

4

5

6

7

8

9
(1.4)

Vicente: and $\uparrow$ he:re,

(0.3)

Vicente: $\quad{ }^{\circ} \mathrm{pf:}:{ }^{\circ}$

Mariana: $\quad$ sometimes girl have

a flag of Brazil

but to wear around

their waist $=$

Mariana: $\quad=$ [ hahahahaha ]

Amanda:

Marta:

[ hahahahaha ]

$\left[{ }^{\circ}\right.$ hahahahaha ${ }^{\circ}$ ]

[ hahahahaha ]

(0.7)

Vicente: during what? during:, sul folia during:,

(0.4)

Mariana: no the::[::: ]

Amanda: [no $>$ in] the beach $<=$

Mariana: $\quad=>$ in the beach $<$ (.)

Vicente: $\quad \uparrow$ oh:

$(0.4)$

Mariana: $\quad$ yeah you've never seen those things that girls wear around the waist you ${ }^{\circ} \mathrm{know} \mathrm{so}{ }^{\circ}$ (0.6)

Mariana: $\quad>$ yeah< tho:se bi:g $(0.5)$

Mariana:
Adriano:

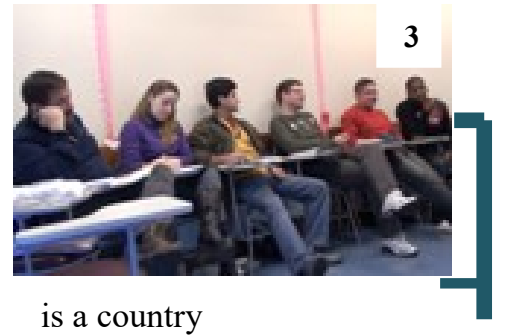

(1.0)

Ramiro:

Ramiro:

yeah

(2.9)

$>$ did you listen?<

(0.3)

Ramiro:

Adriano:

$\underline{\text { Rafael Rafael }}$

Rafael

(Rafael)

(1.0)

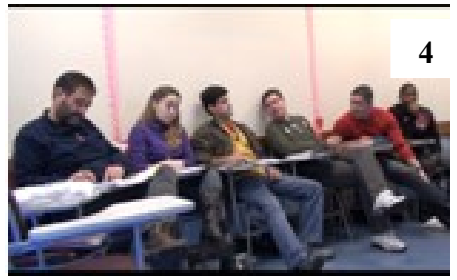

Ramiro:

Adriano:

Rafael:

Adriano:

Ramiro:

Rafael:

Adriano:

Adriano:

Rafael:

Adriano:

is a country

is a cou:ntry (.)

yes Rio Grande do

Sul

(2.4)

no comments $h(h) a ̃$

(1.0)

is a (.) is a

wor:ld

h(h)ãhãhã

no comments.hh

${ }^{\circ}$ hãhã

(.)

oh: yeah

I prefer no comments.hh

(.)

oh: yeah

((Rafael sorri)) 
Como é possível observar no excerto 2, o piso conversacional, que até então era único, divide-se em duas interações distintas que ocorrem simultaneamente e estão inter-relacionadas. No lado esquerdo do cisma, a maior parte dos participantes dá prosseguimento ao piso conversacional que era único até então, sendo esta a conversa principal. Já no lado direito do cisma há o novo piso conversacional que se inicia, envolvendo os participantes Adriano, Ramiro e Rafael.

No cisma do lado esquerdo da transcrição, Vicente inicia uma comparação entre o patriotismo norte-americano e o brasileiro (linha 30), enquanto Mariana traz como exemplo de patriotismo brasileiro o fato de meninas usarem uma bandeira do Brasil em suas cinturas (linhas 33-36), sendo ratificada pelos risos simultâneos de Amanda, Marta e Tito (linhas 38-40). Vicente, então, indaga quando esse uso da bandeira acontece (linhas 42-44) e Amanda afirma que a bandeira é usada pelas meninas na praia (linhas 47 e 48), sendo ratificada por Mariana (linha 49).

Enquanto isso, no lado direito do cisma, a partir do turno produzido por Adriano nas linhas 29 e 30 (Rio Grande do Sul is a country), estabelece-se um piso conversacional paralelo entre ele, Ramiro e Adriano, que se olham enquanto Adriano fala (quadro de imagem 3). Ramiro exibe sua concordância (linha 32), inclina seu tronco na direção de Rafael e, buscando sua afiliação com a posição de Adriano de que o Rio Grande do Sul é um "país”, indaga se Rafael ouviu o que Adriano disse (linha 34) e insiste, chamando Rafael nominalmente por três vezes (linhas 36 e 37), sendo acompanhado por Adriano (linha 38) (quadro de imagem 4).

A seguir, Ramiro reforça a posição de Adriano (linha 40), que o ratifica (linhas 41-43). Rafael, então, ao produzir o turno no comments h(h)ã (linha 45) e reiterá-lo nas linhas 54 e 55, afilia-se à posição dos dois participantes, parecendo demonstrar que emitir a opinião de que o Rio Grande do Sul é um "país" é algo delicado e não deve ser tornado público para o grande grupo. Adriano, ainda, leva sua posição ao extremo, afirmando que o Rio Grande do Sul é um “mundo", e não apenas um "país" (linhas 48 e 49), recebendo novamente a afiliação de Ramiro e Rafael (linhas 49 e 50), que parecem tomar isso como uma crítica ao orgulho de ser gaúcho e, consequentemente, à identidade social de gaúcho, trazida para a interação por Mariana na linha 17. Adriano, portanto, parece estar se opondo à identidade social suscitada por Mariana e tornando relevante na interação sua identidade de "não gaúcho", de não pertencente a este "país" ou "mundo" Rio Grande do Sul. Ramiro e Rafael também mostram interacionalmente a construção dessa identidade social de "não gaúcho" e que isso é algo delicado de ser exposto, em meio a uma turma de gaúchos, incluindo Mariana. 
Cumpre mencionar que, embora seja sabido, por anotações feitas pela durante as filmagens e informações obtidas em conversa com Mariana, que Adriano, Ramiro e Rafael não são gaúchos, tal informação não teria valor ou relevância na análise aqui empreendida, se isso não tivesse ficado visível na interação. $O$ fato da construção e oposição das categorias identitárias de "gaúcho" e "não gaúcho" serem observáveis, não apenas nas falas, mas também em nos gestos, expressões faciais e risos dos participantes, é o que torna possível sua análise interacional.

Nesse sentido, nota-se que são justamente esses três participantes que iniciam o cisma e passam a estabelecer um novo foco interacional, que não guarda mais relação com o tópico do patriotismo norte-americano, mas sim com uma oposição à identidade de "gaúcho" que Mariana trouxe para a interação em seu turno de linha 17. Ao afiliarem-se, Adriano, Ramiro e Rafael, constroem suas identidades de "não gaúchos" momento a momento, de modo local e contingente, sendo o outro fundamental para essa construção, como apontam Moita Lopes (2002) e Giddens (2005). A análise microinteracional empreendida demonstra que a identidade social de "não gaúcho" não foi pré-fixada ou atribuída de antemão aos três participantes, mas sim emergiu e tornou-se evidente na interação, através daquilo que os próprios participantes demonstravam uns aos outros que estavam fazendo e dos significados por eles atribuídos.

Ao mostrarem que não querem tornar pública tal identidade, exibida pelo seu posicionamento de que no Rio Grande do Sul o patriotismo é tão forte, que chega ser um "país", os três participantes demonstram que isso pode gerar uma tensão ou conflito entre eles e os demais, que são gaúchos.

A seguir, veremos que o cisma da interação se encerra quando Mariana direciona o olhar para Adriano, Ramiro e Rafael e solicita que eles compartilhem com o grande grupo aquilo que haviam falado na conversa lateral (linha 61).

\subsection{EXCERTO 3}

$\begin{array}{lll}61 & \text { Mariana: } & \text { What? ((direciona olhar para Adriano, Ramiro e } \\ 62 & & \text { Rafael)) } \\ 63 & \text { Rafael: } & { }^{\circ} \text { nothing } \\ 64 & \text { Adriano: } & \text { ã: [about ã: about ã:] } \\ 65 & \text { Ramiro: } & \text { [Adriano said ã:] Rio Grande do Sul is a } \\ 66 & & \text { country } \\ 67 & & (.) \\ 68 & \text { Adriano: } & \text { about Rio Grande do Sul patriotism } \\ 69 & & (0.3)((\text { Mariana balança a cabeça afirmativamente)) }\end{array}$




\begin{tabular}{|c|c|c|c|}
\hline 70 & Ronaldo: & [ hãhãhã ] & \\
\hline 71 & Tito: & [hãhãhã $\left.{ }^{\circ}\right]$ & \\
\hline 72 & Ramiro: & is a country & \\
\hline 73 & & $()$. & \\
\hline 74 & Vicente: & [oh:: yes ] & \\
\hline 75 & Mariana: & [it's a country] yes. yes. it is. [yeah ] & \\
\hline 76 & Tito: & {$\left[{ }^{\circ} \mathrm{yes}^{\circ}\right]$} & \\
\hline 77 & & (.) & \\
\hline 78 & Adriano: & this is a strong, (1.0) way of the gaúcho & \\
\hline 79 & & {$\left[{ }^{\circ}\right.$ people $\left.{ }^{\circ}\right]$} & \\
\hline 80 & Mariana: & [yeah yeah] feeling $=$ & \\
\hline 81 & Tito: & $=$ yeah it's said it's said the Santa Catarina & \\
\hline 82 & & is the: best $\bar{a}:::=$ & \\
\hline 83 & Ramiro: & $=\mathrm{ah} \downarrow$ na: na- & \\
\hline 84 & Mariana: & [parts of the:: & \\
\hline 85 & Tito: & {$[$ yes $>$ it's the [best part $<$ ] } & \\
\hline 86 & Ramiro: & {$[\text { very good }]^{\circ}$ yeah $^{\circ}=$} & \\
\hline 87 & Tito: & $={ }^{\circ} \mathrm{yes}^{\circ}$ & \\
\hline 88 & Mariana: & ${ }^{\circ}$ yes $^{\circ}=$ & \\
\hline 89 & Adriano: & $=$ best part & \\
\hline 90 & & (.) & \\
\hline 91 & Tito: & because they separate [the: Rio Grande do Sul= & \\
\hline 92 & Adriano: & [hahahahaha & \\
\hline 93 & Tito: & $=$ of(h) the $(\mathrm{h}) \mathrm{re}[\mathrm{st}(\mathrm{h})$ hahahaha & \\
\hline 94 & Marta: & [hahahahahahaha & \\
\hline 95 & Vicente: & [hahahahahahaha & \\
\hline 96 & Adriano: & [hahahahahahaha & \\
\hline 97 & & ((Rafael e Ramiro sorriem)) & \\
\hline 98 & & $(1.5)$ & \\
\hline 99 & Mariana: & $\underline{\mathrm{AH}}(\mathrm{h}):[\because: \quad]$ & \\
\hline 100 & Marta: & [hahaha] & \\
\hline 101 & Tito: & [hahaha]haha[hahaha ] & \\
\hline 102 & Adriano: & [hahaha]haha[hahaha ] & \\
\hline 103 & Rafael: & [alright] & \\
\hline 104 & & $(($ Ramiro e Vicente sorriem $))$ & \\
\hline 105 & Adriano: & ${ }^{\circ}$ hahaha ${ }^{\circ}(($ Ramiro e Ronaldo sorriem $))$ & \\
\hline 106 & Tito: & ${ }^{\circ}$ hahaha ${ }^{\circ}$ & \\
\hline 107 & Mariana: & $(\mathrm{h}) \mathrm{ah}(\mathrm{h})$ & \\
\hline 108 & & $(0.3)$ & \\
\hline 109 & Mariana: & no. but if we (.)we[re to separate from Brazil= & \\
\hline 110 & Vicente: & {$\left[{ }^{\circ}>\right.$ Vitor Ramil $<,(1.2)$ wrote $=$} & \\
\hline 111 & Mariana: & $=$ we would have to] $=$ & \\
\hline 112 & Vicente: & $=$ about that $\left.{ }^{\circ} \quad\right](($ direciona olhar para Amanda $))$ & \\
\hline 113 & Mariana: & $=$ steal $[$ Santa Ca]tarina from them & \\
\hline 114 & Amanda: & {$\left[{ }^{\circ}\right.$ ah yes $\left.{ }^{\circ}\right](($ direciona olhar para } & \\
\hline 115 & & Vicente)) & \\
\hline 116 & Adriano: & [hahah[ haha ] & \\
\hline 117 & Taís: & [hãhãh[ haha ] & \\
\hline 118 & Tito: & [>hãhã $[$ hãhã < ] & \\
\hline 119 & Ramiro: & {$[>$ no no $]$ no $<=(($ Ramiro sorri $))$} & \\
\hline 120 & & ((Tais e Marta sorriem)) & \\
\hline 121 & Adriano: & =>hãhã[hã & \\
\hline 122 & Tito: & $=>$ hãhã[hãhãhã< & \\
\hline 123 & Mariana: & {$[>$ yes: of course $<]>\uparrow$ hahaha $<=$} & \\
\hline 124 & Tito: & $=[$ yes Santa Catarina or Para $\uparrow$ ná the base $=$ & \\
\hline 125 & Ramiro: & [imagine the south of Brazil (is a country)] & \\
\hline 126 & Tito: & $=$ separate: the rest $]$ & \\
\hline 127 & Mariana: & yes: yes: we can have Parana Santa Catarina & \\
\hline
\end{tabular}




\begin{tabular}{|c|c|c|}
\hline 128 & & and $>$ Rio [Grande] do Sul a different $=$ \\
\hline 129 & Ramiro: & [ ã: ]hã \\
\hline 130 & Mariana: & $=$ country $=$ \\
\hline 131 & Ramiro: & $=[\mathrm{hã}(\mathrm{h})$ \\
\hline 132 & Marta: & [hãhãhã \\
\hline 133 & & $(0.8)$ \\
\hline 134 & Mariana: & but it's $\uparrow$ true people- there are people who \\
\hline 135 & & $\uparrow$ fight for that $=$ \\
\hline 136 & Vicente: & $=$ but Tito we do- we have the most beautiful \\
\hline 137 & & woman \\
\hline 138 & & $(0.3)$ \\
\hline 139 & Tito: & [yeah \\
\hline 140 & Vicente: & 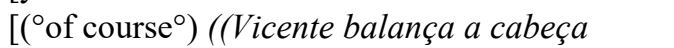 \\
\hline 141 & & afirmativamente)) \\
\hline 142 & Ramiro: & ah no I agree I agree \\
\hline 143 & Marta: & [hahahahaha \\
\hline 144 & Amanda: & [hahahahaha \\
\hline 145 & Mariana: & [hãhãhã HÁ HÁ HÁ HÁ it's ok[(h)ayhahahaha] \\
\hline 146 & Amanda: & [hahahaha $]$ \\
\hline 147 & Ramiro: & [hahahaha]I agree $=$ \\
\hline 148 & Amanda: & $=[$ hahahahahaha \\
\hline 149 & Marta: & $=[$ hahahahahaha \\
\hline 150 & Mariana: & $=[$ hahahahahahahahahahahahahaha]h.h ai ai \\
\hline 151 & & ((Tito, Vicente, Adriano Ramiro e Taís \\
\hline 152 & & sorriem)) \\
\hline 153 & & $(0.3)$ \\
\hline 154 & Mariana: & $>$ alright $<$ anything else that you were talking \\
\hline 155 & & about you think (.)wort $[\mathrm{h} \uparrow \mathrm{me}]$ ntioning \\
\hline 156 & Tito: & {$\left[{ }^{\circ} \mathrm{no}^{\circ}\right]$} \\
\hline 157 & & $(2.7)$ \\
\hline 158 & Mariana: & so. \\
\hline 159 & & $(1.0)$ \\
\hline 160 & Mariana: & what have you decided. are we Brazilians very \\
\hline 161 & & influenced by Americans or not? \\
\hline
\end{tabular}

No excerto 3 observa-se que, ao serem convidados a tornar pública a conversa paralela sobre o patriotismo gaúcho, as ações de Rafael e Adriano evidenciam que, para eles, trata-se de uma questão delicada, que pode gerar tensão e conflito naquele contexto (linhas 63 e 64). Ramiro, no entanto, não hesita em trazer à tona o posicionamento de Adriano, que é também o seu e de Rafael, quanto ao Rio Grande do Sul ser um "país (linhas 65 e 66). A partir desse momento, o foco do piso conversacional principal está diretamente relacionado às identidades sociais de "gaúcho" versus "não gaúcho", que já estavam sendo co-construídas pelos três participantes ao longo da conversa paralela, como vimos. Mariana e Tito, então, não apenas ratificam as falas de Adriano e Ramiro, mas se afiliam à sua posição (linhas 75 e 76), bem como ao reforço trazido por Adriano ao dizer que o "patriotismo gaúcho" é um sentimento forte entre as pessoas do Rio Grande do Sul (linhas 78 e 79).

Como veremos a seguir, a partir desse momento, a oposição interacional, que inicialmente se deu entre as categorias identitárias de Adriano, Ramiro e Rafael ("não gaúchos”) versus as categorias identitárias dos demais participantes ("gaúchos") é reforçada pelo 
posicionamento de alguns participantes, que demonstram concordarem com a ideia de que o estado do Rio Grande do Sul ou os três estados do sul devem separar-se do resto do Brasil, contrariamente à posição de Ramiro, que demonstra discordar de tal ideia.

O novo momento de oposição interacional se dá a partir de uma brincadeira ou piada de Tito quanto ao estado de Santa Catarina ser a melhor parte do Rio Grande do Sul, pois o separa do resto do país (linha 81, 82, 84, 85, 91 e 93). Os participantes orientam-se para a fala de Tito: Adriano, Marta e Vicente riem (linhas 94-96) e Rafael e Ramiro sorriem (quadro de imagem 5). Já Mariana ratifica a ação de Tito ao acrescentar que, se fosse o caso de tal separação ocorrer, o Rio Grande do Sul teria que roubar Santa Catarina do resto do Brasil (linhas 109, 111 e 113), sendo ratificada pelos risos de Adriano, Taís e Tito (linhas 116-122). Ramiro, no entanto, demonstra que se opõe a essa posição tomada pelos demais participantes (linha 119). Tito, então, rindo da proposta de Mariana, acrescenta que Santa Catarina ou o Paraná seriam a base para separar o resto do país (linhas 124 e 126), sendo ratificado por ela (linhas 127-128). Ramiro, por sua vez, ainda discordando da posição tomada por Mariana e Tito, afirma que seria difícil imaginar o sul do Brasil como um país à parte (linha 125).

Vicente, que não havia se manifestado sobre as propostas de Tito e Mariana, orienta-se para Tito, lhe direciona o olhar e pede sua afiliação quanto à sua posição de que no Rio Grande do Sul estão as mulheres mais bonitas (linhas 136 e 137). Tito e Ramiro concordam com tal opinião de Vicente (linha 139, 142 e 147). É interessante notar que Ramiro, que ao longo da interação revelou não concordar com as propostas separatistas trazidas por Tito e Mariana, parece demonstrar que se vê obrigado a concordar com a opinião de Vicente sobre as mulheres gaúchas (linha 142).

Nesse novo momento de posição interacional, percebe-se que alguns itens lexicais usados pelos participantes tornam evidente a construção e reconstrução das identidades "nós, gaúchos" versus “eles, não gaúchos". Aqui, parece que os "não gaúchos" não são mais apenas os participantes Adriano, Ramiro e Rafael, mas sim todos os brasileiros que não são do Rio Grande do Sul. Tito utiliza o pronome "they" para se referir ao estado de Santa Catarina e aos catarinenses, quando produz o turno de fala because they separate [the: Rio Grande do Sul= (linha 91). Já Mariana usa o pronome "we" para se referir ao Rio Grande do Sul e aos gaúchos, também em relação à possível separação (no. but if we (.)we[re to separate from Brazil=, linha 109). Por fim, Vicente usa novamente "we" para fazer alusão ao fato das mulheres mais bonitas serem oriundas

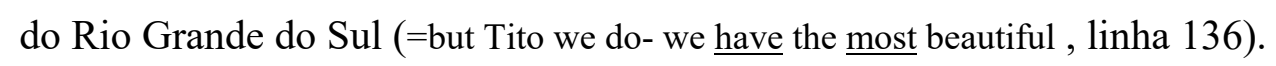

Finalmente, observa-se que a atividade pedagógica se encerra quando Mariana produz o turno >alright. (linha 154) e os participantes mudam seu alinhamento conjunto, passando a se orientar para a finalização do momento de retomada da discussão acerca do tópico "patriotismo". 


\section{CONSIDERAÇÕES FINAIS}

A análise microinteracional apresentada evidenciou que, ao longo da interação, os interagentes exibem uns para os outros que estão se dando conta de quem são e de quem não são, ou seja, atuam como agentes da construção de uma polarização entre as categorias identitárias de "gaúchos” versus "não gaúchos". Assim, primeiramente Adriano, Ramiro e Rafael constroem, de modo conjunto, local e contingente, suas identidades de "não gaúchos", por meio da discordância em relação às colocações de Mariana. Como consequência, as identidades de "gaúchos" são atribuídas à Mariana e aos demais participantes.

Embora a construção da oposição de tais identidades ocorra a partir do novo foco interacional iniciado por Adriano, Ramiro e Rafael, percebemos que tal questão acaba se tornando o tópico da interação principal, diante do questionamento de Mariana. O fato de Rafael e Adriano hesitarem em responder ao seu chamado, mostra que o assunto é considerado delicado e, por isso mesmo, foi tratado em conversa paralela àquela do grande grupo. Quando Adriano compartilha, com o grupo todo, o posicionamento dos três participantes de que o Rio Grande do Sul seria um "país" com forte patriotismo, Vicente, Mariana e Tito imediatamente se afiliam a tal posicionamento e passam a relatar piadas ou brincadeiras comumente feitas acerca do sentimento de orgulho e até mesmo de superioridade dos gaúchos. As identidades de "gaúcho" que Tito e Mariana atribuem a si mesmos - e às pessoas originárias do Rio Grande do Sul - são construídas a partir de uma polarização e explicitamente referidas por meio do uso dos pronomes "nós" e "eles", corroborando o entendimento de que as identidades sociais não são préestabelecidas, mas sim construídas na interação.

Pode-se notar que, ao longo do dado analisado, as identidades sociais construídas pelos participantes acabam por fazê-los agir, em certos momentos, como uma única "parte" na interação, um "time" com uma única unidade social relevante, ao tomarem a mesma posição (LODER, 2006; LERNER, 1993; KANGASHARJU, 2002). Tais alinhamentos dos participantes em "partes" são contingentes, construídos local e sequencialmente para os fins da atividade que está sendo realizada e, portanto, dissolvem-se e reorganizam-se conforme o rumo da interação. É justamente o que ocorre com Adriano, Ramiro e Rafael, ao se afiliarem com a posição de Adriano de que o Rio Grande do Sul é um país. Com o encerramento do cisma e o retorno ao piso conversacional único, Vicente, Mariana e Tito afiliam-se a tal posicionamento, juntando-se ao "time". Logo a seguir, Tito e Mariana agem configurando uma nova única "parte", ao completarem os turnos um do outro e tomarem posição semelhante acerca da separação do Rio Grande do Sul do resto do Brasil e a função de Santa Catarina em tal processo, opondo-se a Ramiro, que discorda de tal posição. 
O estudo demonstra que Mariana, ao acolher e valorizar a contribuição dos demais participantes sobre o patriotismo gáucho, diferente de seu planejamento pedagógico de discussão sobre o patriotismo norte-americano, baseado no livro didático, abriu espaço para que os participantes usassem a língua adicional para agir conforme interesse e contexto local, expondo suas opiniões. Tal abertura apenas pôde se configurar porque Mariana endossou a oposição ou discordância de Adriano, Rafael e Ramiro ao orgulho de ser gaúcho, que, por sua vez, gerou a construção das identidades sociais de "gaúcho" e de "não gaúcho" pelos interagentes, relevantes naquele contexto interacional. Com efeito, se adotarmos uma visão de aprendizagem de língua vinculada à participação em diferentes práticas sociais, a construção de tais categorias identitárias, que emergem da interação, mostra-se como uma prática social significativa, na qual os participantes se engajam. Para tanto, foi exigida a mobilização de recursos linguísticos e extralinguísticos na língua inglesa, a fim de discordarem de Mariana e exporem suas posições. Ambos os processos levados a cabo pelos participantes, de construção das identidades sociais e das oposições interacionais, ocorreram de modo simultâneo e interdependente.

O presente estudo, ao explorar os detalhes das ações realizadas pelos participantes durante o desenvolvimento de uma atividade pedagógica, busca contribuir para uma melhor compreensão acerca do modo pelo qual as categorias identitárias e as oposições são negociadas e construídas conjuntamente e de como o professor pode atuar de modo a incluir tal jogo interacional no processo de ensino e aprendizagem de uma língua adicional. Espera-se que as reflexões aqui expostas possam sensibilizar nós, educadores, sobre a importância da reconfiguração de nosso papel na organização contemporânea de sala de aula. Ao conduzirmos os alunos em seu aprender crítico, nossa atuação não deve focar unicamente no que prevê o livro didático ou o plano pedagógico, restringindo a iniciativa e participação dos alunos. Além disso, o trabalho docente não deve reforçar identidades sociais pré-estabelecidas, pelo contrário, nosso desafio consiste em potencializar as atuações dos alunos e abrir espaço para que conflitos e oposições interacionais e identitários façam parte da aula, tornando o aprendizado mais significativo e, consequentemente, consistente e transformador.

\section{NOTAS}

1 Tal geração de dados se deu inicialmente para fins do estudo apresentado em Autor (2011).

2 Uma vez que a ACE rejeita a imposição prévia de identidades sociais e entende que a cada momento diferentes identidades ou categorias podem emergir da interação, na análise os participantes serão tratados pelos nomes fictícios a eles atribuídos, e não como "professora" e "alunos". 
3 Os dados foram gerados em 2009, tendo sido realizados todos os procedimentos relacionados aos requisitos formais de consentimento informado dos participantes, que manifestaram formalmente sua concordância em serem parte da investigação.

4 As convenções do sistema Jefferson são apresentadas no Anexo.

5 Divisão da conversa "principal" em várias interações que ocorrem ao mesmo tempo e podem voltar a ser unidas em uma conversa única em outro momento interacional.

\section{REFERÊNCIAS}

ATKISON, J. M., \& HERITAGE, J. (Orgs.). Structures of social action. Cambridge: Cambridge University Press, 1984.

AUTOR. XXXXXXX. Dissertação (Mestrado em Letras) - XXXXXX , 2011.

CAZDEN, C. B. Classroom discourse: the language of teaching and learning (2a. ed.). Portsmouth, NH: Heinemann, 2001

CLARK, H. H. The use of language. In: CLARK, H. H., Using language. Cambridge: Cambridge University Press, 1996.

FIRTH, A., \& WAGNER, J. S/FL learning as a social accomplishment: Elaborations on a 'reconceptualized' SLA. Modern Language Journal, 91(5), p. 800-819, 2007.

HELLERMANN, J. \& PEKAREK DOEHLER, S. On the contingent nature of language learning tasks. Classroom Discourse, 1(1), p. 25-45, 2010,

GARDNER, R. Conversation Analysis in the Classroom. In SIDNELL, J. \& STIVERS, T., The Handbook of Conversation Analysis. Blackwell, 2013, p. 593-611.

GARFINKEL, H., \& SACKS, H. On formal structures of practical actions. In McKINNEY, J.C.; TIRYAKIAN, E.A. (Eds.) Theoretical Sociology. New York: Appleton Century Crofts, 1970, p. 337-366.

GIDDENS, A. Sociologia. 4. ed. Porto Alegre: Artmed, 2005.

GOODWIN, C.; GOODWIN, M. H. Participation. In: DURANTI, A. (org.) A companion to Linguistic Anthropology. Oxford: Basil Blackwell, 2004, p. 222-244.

HALL, S. A identidade cultural na pós-modernidade. Rio de Janeiro: DP\&A, 2001.

KANGASHARJU, H. Alignment in disagreement: forming oppositional alliances in committee meetings. Journal of Pragmatics, 34, p. 1447-1471, 2002.

LERNER, G. H. Collectivities in action: establishing the relevance of conjoined participation in conversation. Text, 13(2), p. 213-245, 1993. 
LODER, L. L. O modelo Jefferson de transcrição: convenções e debates. In LODER, L., \& JUNG, N. (orgs.), Fala-em-interação social: introdução à Análise da Conversa Etnometodológica, Porto Alegre: Mercado de Letras, 2008, p. 127-160.

. (2006). Investindo no conflito: a correção pelo outro construindo discordâncias agravadas. Dissertação (Mestrado em Letras) - Universidade Federal do Rio Grande do Sul, Porto Alegre, 2011.

LODER, L. L.; JUNG, N. M. (Org.). Fala-em-interação social: introdução à análise da conversa etnometodológica. Porto Alegre: Mercado de Letras, 2008.

MARKEE, N. \& KASPER, G. Classroom talks: An introduction. The Modern Language Journal, 88(4), p. 491-500, 2004.

MOITA LOPES, L. P. da. Oficina de Linguística Aplicada: a Natureza Social e Educacional dos Processos de Ensino/Aprendizagem de Línguas. Campinas. Mercado de Letras, 1996.

.Identidades Fragmentadas. A construção discursiva de raça, gênero e sexualidade na escola. Campinas: Mercado de Letras, 2002.

MONDADA, L., \& DOEHLER, S. P. Second language acquisition as situated practice: task accomplishment in the French second language classroom. Modern Language Journal, 88(4), p. 501-518, 2004.

PEKAREK-DOEHLER, S. P. Conceptual changes and methodological challenges: on language, learning and documenting learning in conversation analytic SLA research. In SEEDHOUSE, P.; JENKS, C.; WALSH, S. (Eds.), Conceptualising Learning in Applied Linguistics. Basingstoke, UK: Palgrave Macmillan, 2010, p.1-31.

SCHEGLOFF, E. A. Conversation analysis and socially shared cognition. In: RESNICK, L.; LEVINE, , J. M. Levine; BEHREND, S. D. (orgs.), Perspectives on socially shared cognition. Washington: American Psychological Association, 1991, p. 150-171.

SCHULZ, L. A construção da participação na fala-em-interação de sala de aula: um estudo microetnográfico sobre a participação em uma escola municipal de Porto Alegre. Dissertação (Mestrado em Letras) - Universidade Federal do Rio Grande do Sul, Porto Alegre, 2007.

STIVERS, T. Stance, alignment, and affiliation during storytelling: when noddings a token of affiliation. Research on Language and Social Interaction, 41(1), 31- 57, 2008.

STEENSIG, J. Conversation Analysis and Affiliation and Alignment. The Encyclopedia of Applied Linguistics. Oxford: Blackwell, 2012. 
ANEXO: CONVENÇÕES DE TRANSCRIÇÃO*

\begin{tabular}{|c|c|c|}
\hline • & (ponto final) & entonação descendente \\
\hline$?$ & (ponto de interrogação) & entonação ascendente \\
\hline , & (vírgula) & entonação de continuidade \\
\hline- & (hífen) & marca de corte abrupto \\
\hline$\uparrow \downarrow$ & (flechas para cima e para baixo) & $\begin{array}{l}\text { alteração de timbre (mais agudo e mais } \\
\text { grave) }\end{array}$ \\
\hline$::$ & (dois pontos) & prolongamento do som \\
\hline nunca & (sublinhado) & sílaba ou palavra enfatizada \\
\hline PALAVRA & (maiúsculas) & fala em volume alto \\
\hline${ }^{\circ}$ palavra ${ }^{\circ}$ & (sinais de graus) & fala em voz baixa \\
\hline$>$ palavra $<$ & (sinais de maior do que e menor do que) & fala acelerada \\
\hline$<$ palavra $>$ & (sinais de menor do que e maior do que) & fala desacelerada \\
\hline hh & (série de h's) & aspiração ou riso \\
\hline.$h h$ & (h's precedidos de ponto) & inspiração audível \\
\hline$\left[\begin{array}{ll}1 & 1\end{array}\right.$ & (colchetes) & fala simultânea ou sobreposta \\
\hline$=$ & (sinais de igual) & elocuções contíguas \\
\hline$(2,4)$ & (números entre parênteses) & $\begin{array}{l}\text { medida de silêncio (em segundos e } \\
\text { décimos de segundos) }\end{array}$ \\
\hline (.) & (ponto entre parênteses) & micropausa, até $2 / 10$ de segundo \\
\hline ) & (parênteses vazios) & $\begin{array}{l}\text { segmento de fala que não pôde ser } \\
\text { transcrito }\end{array}$ \\
\hline (palavra) & (segmento de fala entre parênteses) & transcrição duvidosa \\
\hline \multicolumn{3}{|c|}{ CONVENÇÕES DE TRANSCRIÇÃO REFERENTES A ELEMENTOS NÃO VERBAIS } \\
\hline ((olhando para o teto $))$ & (parênteses duplos) & descrição de atividade não-vocal \\
\hline
\end{tabular}

*Adaptado de Atkinson e Heritage (1984, p. IX-XVI), Ochs, Schegloff, e Thompson (1996, p.461-465) e das instruções para submissão de artigos ao periódico especializado Research on Language and Social Interaction. 